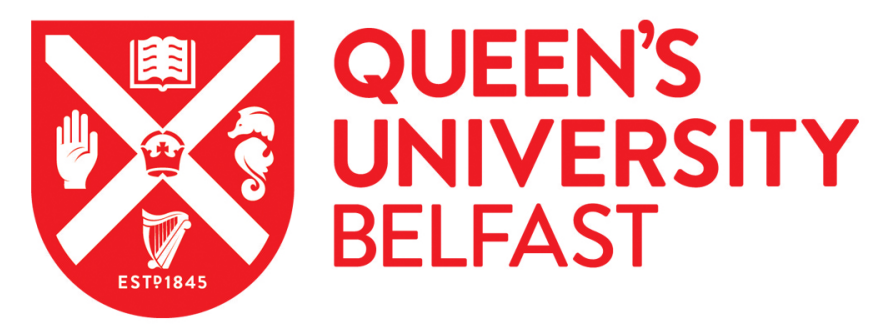

\title{
Dissociative Recombination of D3S+: Product Branching Fractions and Absolute Cross Sections
}

Kaminska, M., Vigren, E., Zhaunerchyk, V., Geppert, W. D., Roberts, H., Walsh, C., Millar, TJ., Danielsson, M., Hamberg, M., Thomas, R. D., Larsson, M., Af Ugglas, M., \& Semaniak, J. (2008). Dissociative Recombination of D3S+: Product Branching Fractions and Absolute Cross Sections. Astrophysical Journal, 681(2), $1717-1724$. https://doi.org/10.1086/588092

Published in:

Astrophysical Journal

Queen's University Belfast - Research Portal:

Link to publication record in Queen's University Belfast Research Portal

\section{General rights}

Copyright for the publications made accessible via the Queen's University Belfast Research Portal is retained by the author(s) and / or other copyright owners and it is a condition of accessing these publications that users recognise and abide by the legal requirements associated with these rights.

Take down policy

The Research Portal is Queen's institutional repository that provides access to Queen's research output. Every effort has been made to ensure that content in the Research Portal does not infringe any person's rights, or applicable UK laws. If you discover content in the Research Portal that you believe breaches copyright or violates any law, please contact openaccess@qub.ac.uk. 


\title{
DISSOCIATIVE RECOMBINATION OF $\mathrm{D}_{3} \mathrm{~S}^{+}$: PRODUCT BRANCHING FRACTIONS AND ABSOLUTE CROSS SECTIONS
}

\author{
M. Kamińska, ${ }^{1,2}$ E. Vigren, ${ }^{2}$ V. Zhaunerchyk, ${ }^{2}$ W. D. Geppert ${ }^{2}$ H. Roberts, ${ }^{3}$ C. Walsh, ${ }^{3}$ \\ T. J. Millar, ${ }^{3}$ M. Danielsson, ${ }^{2}$ M. Hamberg, ${ }^{2}$ R. D. Thomas, ${ }^{2}$ \\ M. Larsson, ${ }^{2}$ M. af UGglas, ${ }^{4}$ and J. SemaniaK ${ }^{1}$ \\ Received 2008 January 25; accepted 2008 March 6
}

\begin{abstract}
The dissociative recombination (DR) of $\mathrm{D}_{3} \mathrm{~S}^{+}$has been studied at the heavy ion storage ring CRYRING. The absolute DR cross sections have been measured over the interaction energy range between $\sim 0$ and $0.1 \mathrm{eV}$, and the energy-dependent cross section obtained is best fitted by the expression $\sigma(E)=(1.3 \pm 0.3) \times 10^{-16} E^{-1.36 \pm 0.04} \mathrm{~cm}^{2}$. From the cross section the thermal rate coefficient has been deduced to be $(2.8 \pm 0.7) \times 10^{-7}(T / 300)^{-0.86 \pm 0.03} \mathrm{~cm}^{3} \mathrm{~s}^{-1}$. The branching fractions in the reaction have been measured at $\sim 0 \mathrm{eV}$ collision energy. The break-up into $\mathrm{D}_{2} \mathrm{~S}+\mathrm{D}$ occurs with a probability of only $0.17 \pm 0.08$, whereas the three-body channel DS $2 \mathrm{D}$ dominates with a probability of $0.58 \pm 0.11$. The remaining channels $\mathrm{DS}+\mathrm{D}_{2}$ and $\mathrm{S}+\mathrm{D}_{2}+\mathrm{D}$ contribute with $0.15 \pm 0.07$ and $0.10 \pm 0.06$, respectively. The impact of these results on the sulfur chemistry and deuterium fractionation in dark molecular clouds was investigated through chemical kinetic models. With these data, the calculated fractional abundance of $\mathrm{H}_{2} \mathrm{~S}$ is lower than observed in TMC-1, which supports the assertion that $\mathrm{H}_{2} \mathrm{~S}$ is formed on grain surfaces and not through gas-phase reactions.

Subject headings: ISM: clouds — ISM: molecules — methods: laboratory — molecular processes

Online material: color figures
\end{abstract}

\section{INTRODUCTION}

Dissociative recombination (DR) describes the reaction sequence in which a singly charged molecular ion captures an electron to form a highly excited neutral molecule which subsequently dissociates into neutral fragments (atoms or molecules). Since DR in general possesses no energy barrier and occurs very efficiently at low interaction energies, it is a crucial reaction in cold plasmas such as molecular clouds and planetary atmospheres (Larsson 1997). In these media, $\mathrm{H}_{2} \mathrm{~S}$ is one of the most widely observed sulfur-bearing molecules. Its formation is, however, dependent on the prevalent environmental conditions (van der Tak et al. 2003).

$\mathrm{H}_{2} \mathrm{~S}$ has been detected in various extraterrestrial environments, e.g., in the low-mass star-forming region L1689N (Wakelam et al. 2004), the star-forming region OMC-1 (Minh et al. 1990), the galactic core NGC 253 (Martín et al. 2005), the complex protostellar system IRAS 16293-2422 (van Dishoeck et al. 1995), and the Jovian atmosphere (Lodders 2004). Lucas \& Liszt (2002) reported the first $\mathrm{H}_{2} \mathrm{~S}$ detection in diffuse clouds, while its presence in dense clouds was reported earlier, e.g., in TMC-1 (Minh et al. 1989) and L134N (Ohishi \& Kaifu 1998).

In dense interstellar clouds, dihydrogen sulfide is believed to be formed in the gas phase via a sequence of reactions initiated by the reaction between neutral sulfur and $\mathrm{H}_{3}^{+}$(Prasad \& Huntress 1982):

$$
\mathrm{S}+\mathrm{H}_{3}^{+} \rightarrow \mathrm{HS}^{+}+\mathrm{H}_{2}
$$

\footnotetext{
${ }^{1}$ Institute of Physics, Jan Kochanowski University, Świetokrzyska 15, PL25406, Kielce, Poland.

2 Department of Physics, Albanova University Center, Stockholm University, SE-106 91, Stockholm, Sweden.

3 Astrophysics Research Centre, School of Mathematics and Physics, Queen's University Belfast, Belfast BT7 1NN, UK.

${ }^{4}$ Manne Siegbahn Laboratory, Freskativägen 24, SE-104 05, Stockholm, Sweden.
}

However, reactions of the type

$$
\mathrm{H}_{n} \mathrm{~S}^{+}+\mathrm{H}_{2} \rightarrow \mathrm{H}_{n+1} \mathrm{~S}^{+}+\mathrm{H} \quad(n=0,1,2)
$$

are highly endothermic and cannot occur in cold interstellar clouds (Millar \& Herbst 1990), and therefore $\mathrm{H}_{3} \mathrm{~S}^{+}$as a precursor of $\mathrm{H}_{2} \mathrm{~S}$ is most likely produced in the radiative association reaction

$$
\mathrm{HS}^{+}+\mathrm{H}_{2} \rightarrow \mathrm{H}_{3} \mathrm{~S}^{+}+h \nu .
$$

Subsequently, $\mathrm{H}_{3} \mathrm{~S}^{+}$can dissociate after recombination with a free electron, yielding $\mathrm{H}_{2} \mathrm{~S}$. However, at low temperatures the rate coefficient for reaction (3) is very low, $\sim 3.5 \times 10^{-15} \mathrm{~cm}^{3} \mathrm{~s}^{-1}$ at $10 \mathrm{~K}$ (Herbst et al. 1989), limiting the number of $\mathrm{H}_{2} \mathrm{~S}$ molecules produced in cold clouds via the dissociative recombination (DR) of $\mathrm{H}_{3} \mathrm{~S}^{+}$.

$\mathrm{H}_{3} \mathrm{~S}^{+}$might be one of the minor molecular ions in the coma of Comet Halley, contributing to the peak with a mass-to-charge ratio of 35 detected by the ion mass spectrometer on the Giotto spacecraft observed at distances $<1000 \mathrm{~km}$. At larger distances from the comet core, DR is thought to be the major loss mechanism for $\mathrm{H}_{3} \mathrm{~S}^{+}$(Haider \& Bhardwaj 2005).

In molecular clouds, the observed abundance ratio of deuteriumcontaining molecules and their H-bearing analogs is usually 1000 times higher than the total cosmic $\mathrm{D} / \mathrm{H}$ ratio of $10^{-5}$ (Roueff et al. 2000). It is evident that in such environments the formation of heavy, deuterated molecules is more favorable. Although this is a relatively well-understood chemical process (replacing an $\mathrm{H}$ atom with $\mathrm{D}$ typically lowers the ground-state energy level of the molecule by several hundred $\mathrm{cm}^{-1}$; Rodgers \& Charnley 2002), observations in the last few years of doubly and triply deuterated species have renewed interest in the deuterium fractionation occurring in dense clouds. Among the many deuterated molecules that have been observed, there exist four sulfur-bearing ones: HDS and $\mathrm{D}_{2} \mathrm{~S}$ have been detected toward several protostars and dense cores (van Dishoeck et al. 1995; Vastel et al. 2003), HDCS 
toward TMC-1 (Minowa et al. 1997), and $\mathrm{D}_{2} \mathrm{CS}$ toward the dark cloud Barnard 1 (Marcelino et al. 2005). Deuteration of $\mathrm{H}_{2} \mathrm{~S}$ by $\mathrm{H}_{2} \mathrm{D}^{+}, \mathrm{HD}_{2}^{+}$or $\mathrm{D}_{3}^{+}$followed by $\mathrm{DR}$ under expulsion of an $\mathrm{H}$ atom could lead to the HDS formation. Therefore, in this study we will also investigate to what extent deuterium fractionation of sulfurbearing compounds is affected by branching fractions of $\mathrm{D}_{3} \mathrm{~S}^{+}$.

In this paper we report on the cross section and complete neutral product branching fractions in the DR of $\mathrm{D}_{3} \mathrm{~S}^{+}$. The fully deuterated isotopologue of $\mathrm{H}_{3} \mathrm{~S}^{+}$was used in the experiment in order to provide better mass separation of the DR products on a detector. We expect that the isotope effect is not significant for the values of the branching fractions. We used the obtained data to investigate their effect on the sulfur chemistry and deuterium fractionation in dark clouds by performing model calculations.

\section{EXPERIMENT}

The experiment has been carried out at the heavy-ion storage ring CRYRING at the Manne Siegbahn Laboratory in Stockholm, Sweden. For the ion production, a hollow cathode ion source JIMIS (Peterson et al. 1998) was used with a gas mixture of $\mathrm{D}_{2}$ and $\mathrm{D}_{2} \mathrm{~S}\left(96 \%{ }^{32} \mathrm{~S}\right)$. The ions were extracted from the source at $40 \mathrm{keV}$, and after mass selection in a bending magnet, injected into the storage ring. The ion mass $40 \mathrm{amu}\left(\mathrm{D}_{3}^{34} \mathrm{~S}^{+}\right)$was chosen to minimize possible isotope contamination. The ions were further accelerated in the ring by a radio frequency cavity to the maximum energy $2.4 \mathrm{MeV}$ allowed by the magnetic rigidity of the ring and stored for $3 \mathrm{~s}$ prior to the measurements.

CRYRING is a nearly circular ion storage ring (circumference of $51.6 \mathrm{~m}$ ), which consists of 12 straight sections separated by bending magnets. One of the sections is equipped with an electron cooler, where the stored ion beam interacts colinearly with a monoenergetic electron beam over a distance of $85 \mathrm{~cm}$. The electron beam is characterized by an anisotropic Maxwellian distribution with estimated transversal and longitudinal temperatures of $k T_{\perp}=2 \mathrm{meV}$ and $k T_{\|}=0.1 \mathrm{meV}$, respectively. Any neutral fragment originating from reactions occurring in the interaction region remains unaffected by the magnetic field of the bending magnet following the electron cooler, and leaves the ring tangentially. The neutral fragments are detected with a surface barrier detector. In the present experiments two detectors with active areas of 900 and $3000 \mathrm{~mm}^{2}$ were used, which were located at distances of $\sim 3.8$ and $\sim 4.2 \mathrm{~m}$ from the center of the electron cooler, respectively. The small detector has higher energy resolution, but due to the smaller geometrical size, some particles which gain a sufficiently large transverse kick from the reaction can miss it. Therefore, the large detector was used in the measurements of DR cross sections, while the branching fractions were measured with the small detector. The output signal from the detector is proportional to the kinetic energy of the incoming particles deposited in the active region of the detector. This signal after amplification with a linear amplifier was monitored by a MultiChannel Analyzer (MCA) to give a pulse-height spectrum. For measurements of the reaction cross section, the DR count rate was measured by discriminating any signals with amplitude other than that corresponding to the full beam energy and recording the signal versus storage time with a MultiChannel Scaler (MCS).

\section{DATA ANALYSIS}

\subsection{Cross Section}

The DR cross section is investigated as a function of the interaction energy, or detuning energy $E_{d}$, given by

$$
\sqrt{E_{d}}=\sqrt{E_{e}}-\sqrt{E_{\mathrm{cool}}}
$$

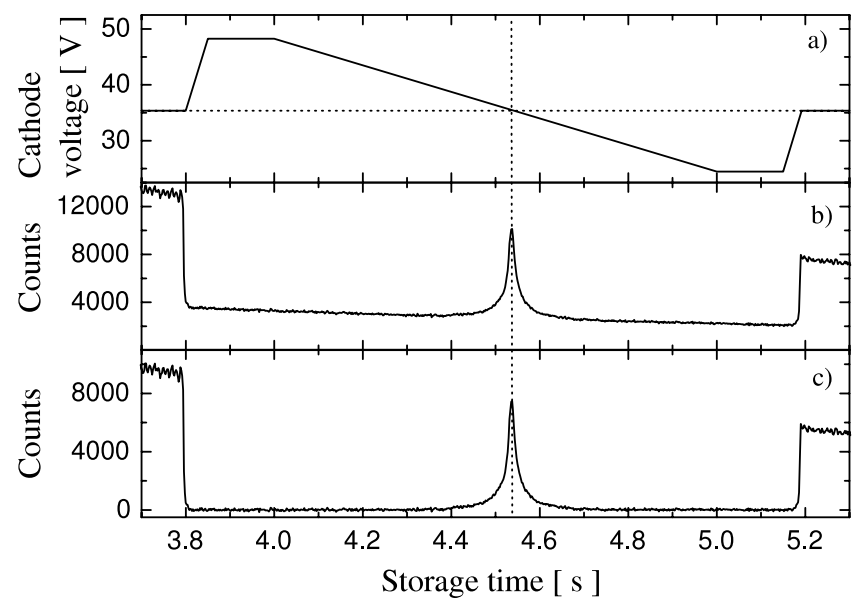

FIG. 1.- (a) Cathode voltage vs. storage time during cross section measurement. (b) The DR signal+background recorded with the MCS. (c) The pure DR signal obtained after the subtraction of background.

where $E_{e}$ is the kinetic energy of the electrons and $E_{\text {cool }}$ is the cooling energy, which is the kinetic energy of electrons when they have the same velocity as the ions. When the detuning energy $E_{d}$ is much higher than $k T_{\perp}$, equation (4) determines the center-ofmass collision energy. The energies $E_{e}$ and $E_{\text {cool }}$ can be expressed in terms of the electron gun cathode voltage corrected for the space charge effect in the electron beam (Kilgus et al. 1992) and its partial neutralization by trapped positive ions (Semaniak et al. 1998). After each injection and acceleration of the ions, the electron gun cathode voltage was altered as a function of time according to the scheme plotted in Figure 1 $a$, which allowed us to scan the collision energy from $\sim 0$ to $1 \mathrm{eV}$ twice, with the electrons moving faster and slower than the ions. The data obtained are plotted in Figure $1 b$. The DR cross section at a collision energy of $1 \mathrm{eV}$ is negligible, and thus the corresponding count rate recorded with the surface barrier detector can serve as a measure of events due to background processes generated in charge-transfer reactions with residual gas. By assuming an exponential time dependence of the ion beam current, the measured background count rate was interpolated over the whole time range and subtracted from the total signal, yielding a pure DR count rate as shown in Figure 1c.

The measured DR rate coefficient $\alpha\left(E_{d}\right)$, which is the velocityweighted cross section, averaged over the electron velocity distribution in the electron beam, was derived using the expression

$$
\alpha\left(E_{d}\right)=\frac{d N_{\mathrm{DR}}}{d t} \frac{v_{e} v_{i} e^{2} r_{e}^{2} \pi}{I_{e} I_{i} l},
$$

where $d N_{\mathrm{DR}} / d t$ is the recorded count rate of DR events, $e$ is the elementary charge, $v_{e}$ and $v_{i}$ are electron and ion velocities in the laboratory frame of reference, respectively, $l$ is the length of the parallel interaction region, and $r_{e}$ is the radius of the electron beam with a current of $I_{e}$. The ion-beam current $I_{i}$ in the present experiments was typically $3.9 \mathrm{nA}$. The method employed to measure the current is explained in detail elsewhere (Paál et al. 2004).

The measured rate coefficient was corrected for the so-called toroidal effect (Lampert et al. 1996). Finally, the DR cross section could be found by dividing the derived rate coefficient $\alpha\left(E_{d}\right)$ by the detuning velocity $v_{d}$, which is defined as $v_{d}=\left(2 E_{d} / m_{e}\right)^{1 / 2}$, where $m_{e}$ is the electron mass. This procedure can be applied as long as the collision energy is larger than the energy spread of the electrons. Otherwise, a numerical Fourier transform technique (Mowat et al. 1995) is implemented to deconvolute the cross 
section from the measured rate coefficient; this was done in the present work.

The thermal rate coefficient as a function of the electron temperature $T$ was obtained by integrating the absolute cross section $\sigma(E)$ over the electron energy distribution in thermal equilibrium conditions:

$$
\alpha(T)=\frac{8 \pi m_{e}}{\left(2 \pi m_{e} k T\right)^{3 / 2}} \int_{0}^{\infty} E \sigma(E) e^{-E / k T} d E .
$$

\subsection{Product Branching Fractions}

In the DR of the $\mathrm{D}_{3} \mathrm{~S}^{+}$ions with near-zero $\mathrm{eV}$ electrons, the following channels are energetically accessible:

$$
\mathrm{D}_{3} \mathrm{~S}^{+}+e^{-} \rightarrow\left\{\begin{array}{l}
\mathrm{D}_{2} \mathrm{~S}+\mathrm{D}+6.22 \mathrm{eV} \\
\mathrm{DS}+2 \mathrm{D}+2.3 \mathrm{eV} \\
\mathrm{DS}+\mathrm{D}_{2}+6.82 \mathrm{eV} \\
\mathrm{S}+\mathrm{D}_{2}+\mathrm{D}+3.13 \mathrm{eV}
\end{array}\right.
$$

The energetics quoted here are obtained from calculations using the fully hydrogenated molecules, and it is assumed that isotopic shift for deuterated species will be not significant, and that the products are formed in the ground state. The products of a DR reaction reach the detector within a time interval shorter than the pulse shaping time of the detector amplifier. In order to determine the product branching fractions, a grid with a transmission of $t=0.297 \pm 0.015$ (Neau et al. 2000) was inserted in front of the surface barrier detector. The probability for a particle to be stopped by the grid or pass through is $1-t$ and $t$, respectively. The output signal from the detector has amplitude proportional to the energy carried by the fragments. The fragment with a mass of $M_{x}$ has an energy that is the fraction of the full beam energy $E_{\text {tot }}$ given by $E_{\text {tot }} M_{x} / M_{\text {tot }}$, where $M_{\text {tot }}$ is the mass of the ion. Consequently, the pulse-height spectrum of the DR products with the grid in front of the detector is no longer a single peak with an amplitude corresponding to the full ion beam energy. Instead it consists of a series of peaks at different positions defined by the energy carried by the fragments passing through the grid. These intensities can be expressed in terms of the product branching fractions and the transmission probability. For example, neutral DR products produced in dissociation channel $\alpha$ can be detected either with the total ion beam energy with a probability of $t^{2}$, or with the energy carried by the $\mathrm{D}_{2} \mathrm{~S}$ fragment with a probability of $t(1-t)$, or with the energy carried by the $\mathrm{D}$ fragment with the same probability $t(1-t)$. The neutral product pulse-height spectra were recorded with the electron beam energy tuned to collision energy of both $\sim 0 \mathrm{eV}$ (Fig. $2 a$ ) and $1 \mathrm{eV}$ (Fig. 2b). Simultaneously, the ion beam intensity was monitored with an MCP detector located in another straight section of the ring. The background spectrum registered at $1 \mathrm{eV}$ is assumed to be dominated by products from collisions of the ions with residual gas (since the DR cross section at this energy is vanishingly small). Both spectra, after being normalized to the intensity of the ion beam measured with the MCP detector, were subtracted from each other, thus yielding a neutral product pulse-height distribution spectrum (Fig. $2 c$ ) resulting purely from DR reactions.

The energy resolution of the smaller detector was sufficient to resolve deuterium peaks (Fig. 2). However, the peaks originating from fragments containing a sulfur atom were not resolved in the pulse-height spectrum of DR products. In order to determine the intensities of individual peaks, their positions and widths have been assumed to be the same as were found in the background spectrum recorded at $1 \mathrm{eV}$ in which they were resolved (Fig. 2b).

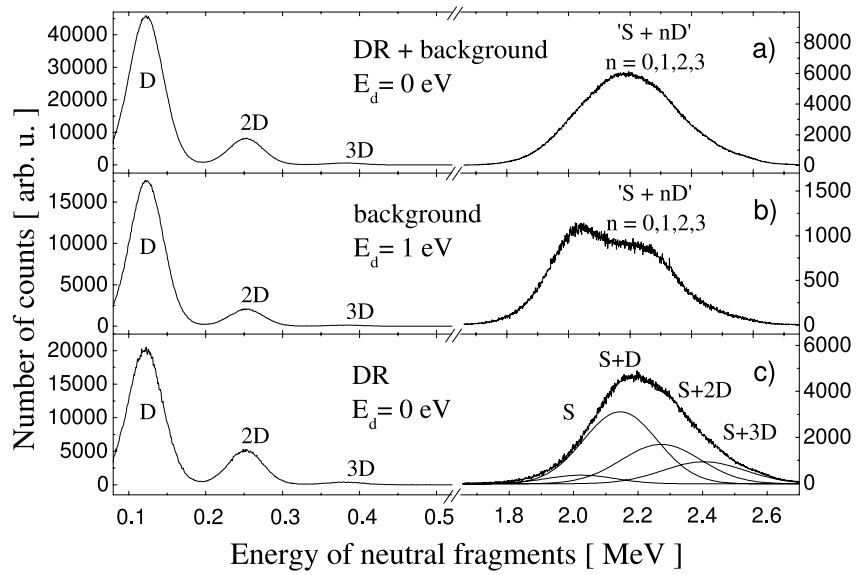

FIG. 2.-Energy spectra of neutral fragments from DR of $\mathrm{D}_{3} \mathrm{~S}^{+}$measured with the grid in front of the detector. (a) The spectrum measured with a detuning energy of $0 \mathrm{eV}$. (b) Background spectrum collected after changing the detuning energy to $1 \mathrm{eV}$. (c) The pure DR spectrum obtained after the subtraction of the background with Gaussian fits of the individual sulfur peaks.

Moreover, the detector did not allow the detection of all DR products, because the maximum transversal separations of some light products were larger than the active area of the detector. The loss events influence the intensities of individual peaks in the pulseheight spectrum of the DR products, and therefore corrections have to be done to account for this effect. From simple investigation into two-body channels energetics, we found that the kinetic energy release in those dissociation channels is high enough to make some of the $\mathrm{D}$ or $\mathrm{D}_{2}$ fragments evade the detector. However, for the DS+2D channel a Monte Carlo simulation of the velocity/energy of the fragments from those DR reactions was performed to investigate this effect. The procedure is described in detail elsewhere (Thomas et al. 2002). Analysis of the results from the simulation showed that in channel DS $+2 \mathrm{D}$, the losses were negligibly small and thus they should not contribute to the final result. Three correction factors, $L_{\alpha}, L_{\gamma}$, and $L_{\delta}$ for channels $\alpha, \gamma$, and $\delta$, respectively, representing probabilities that one deuterium atom (or $\mathrm{D}_{2}$ molecule in case of $L_{\gamma}$ ) can miss the detector, were implemented in order to take this situation into account. With these factors the intensities of the peaks in the pulseheight spectrum can be described by the set of equations (8) expressed in terms of the grid transmission, $t$, and the number of events in individual dissociation channels $N_{\alpha}, N_{\beta}, N_{\gamma}$, and $N_{\delta}$ :

$$
\left(\begin{array}{c}
I_{\mathrm{D}} \\
I_{2 \mathrm{D}} \\
I_{3 \mathrm{D}} \\
I_{\mathrm{S}} \\
I_{\mathrm{S}+\mathrm{D}} \\
I_{\mathrm{S}+2 \mathrm{D}} \\
I_{\mathrm{S}+3 \mathrm{D}}
\end{array}\right)=T_{\mathrm{D}_{3} \mathrm{~S}^{+}} \times\left(\begin{array}{c}
N_{\alpha} \\
N_{\beta} \\
N_{\gamma} \\
N_{\delta}
\end{array}\right),
$$

where the matrix $T_{\mathrm{D}_{3} \mathrm{~S}^{+}}$is given in Appendix equation (A1).

As seen from this set of equations, only one dissociation channel can contribute to the peaks resulting from detection of three deuterium atoms or a single sulfur atom. Therefore, the correction factor $L_{\delta}$ can be analytically derived from rows 3 and 4 in equation (8) as

$$
\frac{I_{3 D}}{t^{2}(1-t) L_{\delta}^{*}}=\frac{I_{S}}{t(1-t)^{2} L_{\delta}^{*}+t(1-t) L_{\delta}},
$$




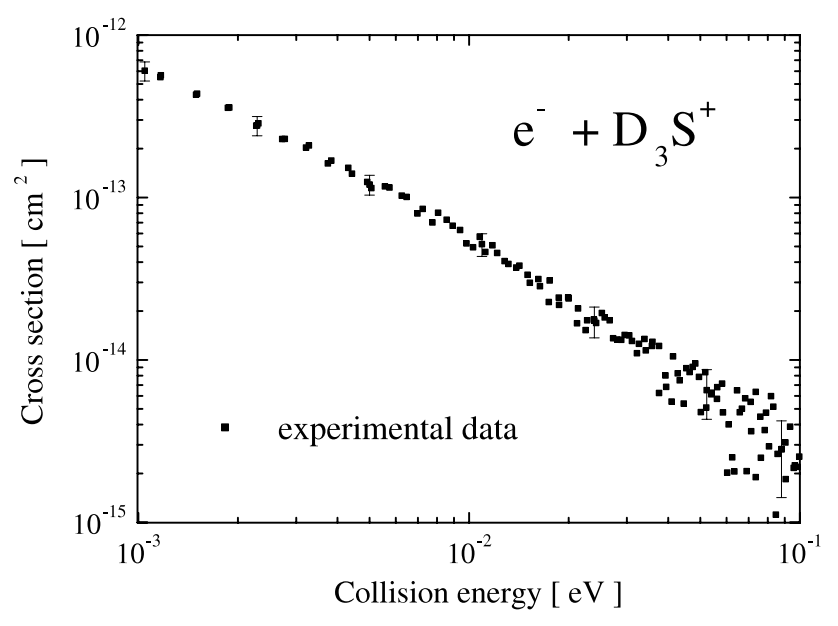

FIG. 3.-Absolute DR cross sections for $\mathrm{D}_{3} \mathrm{~S}^{+}$as a function of collision energy. Filled squares show cross sections obtained by dividing the measured rate coefficient by the detuning velocity.

and used as a fixed parameter in solving the system of equations using a least-squares method. The branching fractions for an individual dissociation channel are finally obtained after the normalization:

$$
\alpha, \beta, \gamma, \delta=\frac{N_{\alpha, \beta, \gamma, \delta}}{N_{\alpha}+N_{\beta}+N_{\gamma}+N_{\delta}} .
$$

\section{RESULTS AND DISCUSSION}

The absolute cross section for the DR of $\mathrm{D}_{3} \mathrm{~S}^{+}$was measured over the energy range $\sim 0-0.1 \mathrm{eV}$ and is plotted in Figure 3 . The energy dependence obtained for the cross section is best fit by the expression $\sigma(E)=(1.3 \pm 0.3) \times 10^{-16} E^{-1.36 \pm 0.04} \mathrm{~cm}^{2}$ over the energy range $1-100 \mathrm{meV}$. The derived energy dependence $E^{-1.36}$ is much steeper than the $E^{-1}$ behavior typical of the direct DR mechanism, according to the Wigner threshold law (Wigner 1948). This result implies that the resonant capture of an electron into Rydberg states and decay via the indirect mechanism plays an important role in the DR of $\mathrm{D}_{3} \mathrm{~S}^{+}$at low energies.

From the measured cross sections, a thermal rate coefficient has been derived yielding $\alpha(T)=(2.8 \pm 0.7) \times 10^{-7}(T /$ $300)^{-0.86 \pm 0.03} \mathrm{~cm}^{3} \mathrm{~s}^{-1}$ over the temperature range of $50-1000 \mathrm{~K}$. The temperature dependence of the rate coefficient is steeper than the $T^{-0.5}$ predicted by theory for the direct mechanism (Bardsley 1968). The thermal reaction rate coefficients for $\mathrm{H}_{3} \mathrm{~S}^{+}$ at $300 \mathrm{~K}$ have been measured previously. The results obtained from flowing afterglow experiments are $3.7 \times 10^{-7} \mathrm{~cm}^{3} \mathrm{~s}^{-1}$ with FALP apparatus (Adams \& Smith 1988), and $5.2 \times 10^{-7} \mathrm{~cm}^{3} \mathrm{~s}^{-1}$ (Abouelaziz et al. 1992) and $5 \times 10^{-7} \mathrm{~cm}^{3} \mathrm{~s}^{-1}$ with FALP-MS apparatus (Rowe et al. 1995). The present results show that the thermal rate coefficient found for $\mathrm{D}_{3} \mathrm{~S}^{+}$is smaller than those reported for $\mathrm{H}_{3} \mathrm{~S}^{+}$. However, the data are not directly comparable, since isotopologue effects are well known. A similar tendency of the smaller rate coefficient for deuterated species has been observed in previous DR studies; see, e.g., $\mathrm{H}_{3} \mathrm{O}^{+}$vs. $\mathrm{D}_{3} \mathrm{O}^{+}$(Neau et al. 2000), $\mathrm{H}_{2} \mathrm{O}^{+}$vs. $\mathrm{HDO}^{+}$(Jensen et al. 1999), and $\mathrm{NH}_{4}^{+}$vs. $\mathrm{ND}^{+}{ }_{4}$ (Öjekull et al. 2004). In the case of protonated water, the rate coefficient at $300 \mathrm{~K}$ for $\mathrm{D}_{3} \mathrm{O}^{+}$was 2 times lower than for $\mathrm{H}_{3} \mathrm{O}^{+}$, and similar ratios were found for the other mentioned ions. If we assumed the same difference between rate coefficients for $\mathrm{D}_{3} \mathrm{~S}^{+}$ and $\mathrm{H}_{3} \mathrm{~S}^{+}$, then the guessed rate for $\mathrm{H}_{3} \mathrm{~S}^{+}$would be $5.6 \pm 1.4 \times$ $10^{-7} \mathrm{~cm}^{3} \mathrm{~s}^{-1}$, which would agree well with the values reported in the previous FALP experiments.
The DR branching fractions derived from the measured data are $0.17 \pm 0.08,0.58 \pm 0.11,0.15 \pm 0.07$, and $0.10 \pm 0.06$ for the dissociation channels $\mathrm{D}_{2} \mathrm{~S}+\mathrm{D}, \mathrm{DS}+2 \mathrm{D}, \mathrm{DS}+\mathrm{D}_{2}$, and $\mathrm{S}+\mathrm{D}_{2}+\mathrm{D}$, respectively. The relatively large error bars are mostly attributed to the uncertainties in the fitting procedure of individual peaks in the measured spectrum. The systematic errors also arise from the uncertainty of the grid transmission, $t=0.297 \pm 0.015$ (Neau et al. 2000). Despite the large uncertainties, it is clear that the DR of $\mathrm{D}_{3} \mathrm{~S}^{+}$occurs mostly through the three-body break-up channel leading to the formation of $\mathrm{DS}+2 \mathrm{D}$.

In several previous storage ring experiments, the same branching fractions within the experimental uncertainties have been measured for several isotopologues in DR reactions: $\mathrm{H}_{3}^{+}, \mathrm{H}_{2} \mathrm{D}^{+}$, and $\mathrm{D}_{2} \mathrm{H}^{+}$(Datz et al. 1995a, 1995b; Zhaunerchyk et al. 2008), $\mathrm{H}_{2} \mathrm{O}^{+}$ and $\mathrm{HDO}^{+}$(Jensen et al. 1999), $\mathrm{H}_{3} \mathrm{O}^{+}, \mathrm{HD}_{2} \mathrm{O}^{+}$, and $\mathrm{D}_{3} \mathrm{O}^{+}$(Neau et al. 2000; Jensen et al. 2000). Therefore, one can assume that branching fractions similar to those of $\mathrm{D}_{3} \mathrm{~S}^{+}$should also be found for $\mathrm{H}_{3} \mathrm{~S}^{+}$.

So far, only partial branching fractions have been measured for the DR of protonated dihydrogen sulfide. The fractional $\mathrm{H}$-atom contributions, $f_{\mathrm{H}}$, which are defined as the average number of $\mathrm{H}$ atoms produced per DR event, have been determined in an experiment combining the flowing afterglow technique with laser-induced fluorescence and vacuum ultraviolet absorption spectroscopy (Adams et al. 1991). Widely divergent $f_{\mathrm{H}}$ values $0.19-$ 0.48 were obtained, depending on different precursor ions used to produce $\mathrm{H}_{3} \mathrm{~S}^{+}$. In the case of $\mathrm{D}_{3} \mathrm{~S}^{+}$, the $\mathrm{D}$ atom fractional contribution deduced from our measurement is $f_{\mathrm{D}}=\alpha+2 \beta+\delta=$ 1.43 , where $\alpha, \beta$, and $\delta$ are branching fractions for the corresponding channels. A branching fraction of $60 \%-80 \%$ for the channel HS $+\mathrm{H}_{2}$ can be deduced from the measured $f_{\mathrm{H}}$ contributions (Rowe et al. 1995), while we report this channel as contributing only $15 \%$. Since the FALP data depend on the conditions present in $\mathrm{H}_{3} \mathrm{~S}^{+}$formation, internal energy effects are critical. It could be the case that collisional quenching was not sufficiently efficient in some of these FALP experiments, and this might account for the differences in results.

One of the theories devised by Bates to predict the branching fractions for different molecules is based on consideration of the valence bonds involved (Bates 1986). It was revised in 1991 (Bates 1991) to explain the experimental data of Adams et al. (1991). In the earlier theory, the favored pathway for dissociation involved the least rearrangement of valence bonds, pointing out the detachment of a single hydrogen atom as the dominant process. However, in 1991, experimental results rectified this original supposition for several molecules, among others $\mathrm{H}_{3} \mathrm{~S}^{+}$. According to the refined version, the most dominant channel would be $\mathrm{HS}+\mathrm{H}_{2}$, with the minor channel $\mathrm{H}_{2} \mathrm{~S}+\mathrm{H}$, occurring with probability of 0.68 and 0.32 , respectively. The dissociation channel $\mathrm{SH}+\mathrm{H}+\mathrm{H}$ was neglected as occurring for electrons with an energy of about $1 \mathrm{eV}$, i.e., at an energy for which the favorable curve crossing exists. The channel $\mathrm{S}+\mathrm{H}_{2}+\mathrm{H}$ was not taken at all into consideration in that model.

A so-called statistical phase-space model by Galloway \& Herbst (1991) was used to obtain the theoretical branching fractions for DR of, e.g., $\mathrm{H}_{3} \mathrm{~S}^{+}$and $\mathrm{H}_{3} \mathrm{O}^{+}$, which were then compared with the experimental results. Comparison of $\mathrm{H}_{3} \mathrm{~S}^{+}$and $\mathrm{H}_{3} \mathrm{O}^{+}$was motivated by the similar electronic structure of the two ions and similar kinetic energy releases in analogous fragmentation channels in reaction with electrons. The model predicts that the fractional $\mathrm{H}$-atom contribution can be as high as 1.28 for $\mathrm{H}_{3} \mathrm{O}^{+}$and 1.31 for $\mathrm{H}_{3} \mathrm{~S}^{+}$for products that are not rotationally excited. For more rotationally excited products, the model predicts a lower fractional $\mathrm{H}$-atom contribution. Therefore, for the FALP data (Adams et al. 
1991) with $f_{\mathrm{H}}=0.19-0.48$ in the DR of $\mathrm{H}_{3} \mathrm{~S}^{+}$and $f_{\mathrm{H}}=0.8-$ 1.16 in the DR of $\mathrm{H}_{3} \mathrm{O}^{+}$Herbst's model suggests high and moderate rotational excitation of the products, respectively. In view of recent storage ring experiments, the $f_{\mathrm{H}}$ reported for the DR of $\mathrm{H}_{3} \mathrm{O}^{+}$are 1.56 at CRYRING (Neau et al. 2000) and 1.463 at ASTRID (Jensen et al. 2000), while in the DR of $\mathrm{D}_{3} \mathrm{~S}^{+}$we report $f_{\mathrm{D}}=1.43$. These results agree well with the prediction of phasespace theory under the assumption of minimal rotational excitation in the neutral products (Galloway \& Herbst 1991).

\section{CHEMICAL MODEL CALCULATIONS}

\subsection{Previous Models}

In the paper by Roberts et al. (2004), a gas-phase plus accretion chemical model of interstellar deuterium chemistry was used with two different reaction networks, the RATE99 model (Le Teuff et al. 2000) and the NSM model (Herbst 2003). The agreement between the two models for molecular $\mathrm{D} / \mathrm{H}$ ratios was generally good, but not for $\mathrm{D}_{2} \mathrm{~S}$. The difference was caused by different branching fractions for the DR of $\mathrm{H}_{3} \mathrm{~S}^{+}$and its isotopologues in the two networks, giving a smaller $\mathrm{D}_{2} \mathrm{~S} / \mathrm{H}_{2} \mathrm{~S}$ ratio with the RATE99 model than with the NSM model. The adopted branching fractions for $\mathrm{H}_{2} \mathrm{~S}$ production from the DR of $\mathrm{H}_{3} \mathrm{~S}^{+}$in the RATE99 and the NSM models were $50 \%$ and $75 \%$, respectively, although the latest version of the NSM model also uses 50\% (Herbst 2007).

The observed $\mathrm{HDS} / \mathrm{H}_{2} \mathrm{~S}$ and $\mathrm{D}_{2} \mathrm{~S} / \mathrm{HDS}$ ratios of 0.1 (van Dishoeck et al. 1995; Vastel et al. 2003) indicate that the fractional abundances of $\mathrm{H}_{2} \mathrm{~S}$ and HDS are on the order of $10^{-9}$ and $10^{-10}$, whereas model calculations yield $\mathrm{H}_{2} \mathrm{~S} / \mathrm{H}_{2} \sim 10^{-11}$ (Roberts et al. 2004). The abundances of saturated species, such as methanol and hydrogen sulfide, predicted by low-temperature ion-molecule chemistry are typically lower than the abundances observed toward star-forming regions. In contrast, the observed deuterium fractionation in these species (particularly toward lowmass protostars) is higher than gas-phase models predict (Parise et al. 2002, 2004; Vastel et al. 2003). Due to the inefficient formation of $\mathrm{H}_{2} \mathrm{~S}$ in the gas-phase and the high observed fractionation, Vastel et al. concluded that $\mathrm{H}_{2} \mathrm{~S}, \mathrm{HDS}$, and $\mathrm{D}_{2} \mathrm{~S}$ must be efficiently formed on the grain surfaces during the cold, dense, pre-protostellar phase. Chemical models of deuterium fractionation in the gas phase (Roberts et al. 2003) require high densities $\left(\sim 10^{6} \mathrm{~cm}^{-3}\right)$ and significant depletion of $\mathrm{CO}$ and $\mathrm{O}$ onto grains to achieve the high initial $\mathrm{D} / \mathrm{H}$ ratio of $>0.1$ needed to reproduce the hydrogen sulfide fractionation, as well as other recent observations of deuterated methanol and formaldehyde (Parise et al. 2002, 2004).

Marcelino et al. (2005) observed deuterated thioformaldehyde toward the dark cloud Barnard 1, with a $\mathrm{D}_{2} \mathrm{CS} / \mathrm{HDCS}$ ratio of 0.33 , and constructed gas-phase models which could reproduce their observations. These models included possible fractionation reactions involving $\mathrm{H}_{2} \mathrm{CS}^{+}, \mathrm{H}_{3} \mathrm{CS}^{+}$, and $\mathrm{H}_{3} \mathrm{~S}^{+}$with $\mathrm{HD}$, together with the assumption that in DR reactions the removal of $\mathrm{H}$ atoms was twice as efficient as that of $\mathrm{D}$ atoms. The calculated fractional abundance of hydrogen sulfide was noted to be between $4 \times 10^{-10}$ and $10^{-9}$, significantly higher than the results from the NSM and RATE99 models above, and in reasonable agreement with the values found by Vastel et al. (2003). This is primarily due to the high elemental sulfur abundance used, $\mathrm{S} / \mathrm{H}_{2}=3.7 \times 10^{-7}$. The fraction of sulfur depleted onto grains in dark clouds vs. that available for reactions in the gas-phase is largely unknown, but the NSM and RATE99 models typically assume $\mathrm{S} / \mathrm{H} \sim 10^{-8}-10^{-7}$.

\subsection{Gas-Phase Chemistry}

We have investigated the effect of the latest experimental measurements on the sulfur chemistry of dark clouds, using time-
TABLE 1

Adopted Rate Coefficients $\alpha=a(T / 300)^{b}$ for DR Reactions

\begin{tabular}{|c|c|c|}
\hline Reaction & $\begin{array}{c}a \\
\left(\mathrm{~cm}^{3} \mathrm{~s}^{-1}\right)\end{array}$ & $b$ \\
\hline $\mathrm{H}_{3} \mathrm{CS}^{+}+e^{-} \rightarrow \mathrm{CS}+\mathrm{H}_{2}+\mathrm{H} \ldots \ldots \ldots \ldots$ & $2(-7)$ & -0.5 \\
\hline $\mathrm{H}_{3} \mathrm{CS}^{+}+e^{-} \rightarrow \mathrm{H}_{2} \mathrm{CS}+\mathrm{H} \ldots \ldots \ldots \ldots \ldots$ & $2(-7)$ & -0.5 \\
\hline $\mathrm{H}_{3} \mathrm{CS}^{+}+e^{-} \rightarrow \mathrm{HCS}+2 \mathrm{H} \ldots \ldots \ldots \ldots \ldots$ & $1(-7)$ & -0.5 \\
\hline $\mathrm{H}_{3} \mathrm{CS}^{+}+e^{-} \rightarrow \mathrm{HCS}+\mathrm{H}_{2} \ldots \ldots \ldots \ldots \ldots$ & $5(-8)$ & -0.5 \\
\hline $\mathrm{H}_{3} \mathrm{CS}^{+}+e^{-} \rightarrow \mathrm{CH}_{2}+\mathrm{HS} \ldots \ldots \ldots \ldots \ldots$ & $4(-8)$ & -0.5 \\
\hline $\mathrm{H}_{3} \mathrm{CS}^{+}+e^{-} \rightarrow \mathrm{CH}+\mathrm{H}_{2} \mathrm{~S} \ldots \ldots \ldots \ldots \ldots$ & $1(-8)$ & -0.5 \\
\hline $\mathrm{HSO}^{+}+e^{-} \rightarrow \mathrm{H}+\mathrm{SO} \ldots \ldots \ldots \ldots \ldots \ldots$ & $1(-7)$ & -0.5 \\
\hline $\mathrm{HSO}^{+}+e^{-} \rightarrow \mathrm{HS}+\mathrm{O} \ldots \ldots \ldots \ldots \ldots \ldots \ldots$ & $5(-8)$ & -0.5 \\
\hline $\mathrm{HSO}^{+}+e^{-} \rightarrow \mathrm{H}+\mathrm{O}+\mathrm{S} \ldots \ldots \ldots \ldots \ldots . . . . .$. & $5(-8)$ & -0.5 \\
\hline
\end{tabular}

Note.-We use $\mathrm{A}(-\mathrm{B})$ notation for $\mathrm{A} \times 10^{-\mathrm{B}}$.

dependent gas-phase chemical kinetic models. The standard dark cloud conditions were used: $T=10 \mathrm{~K}, n(\mathrm{H})=2 \times 10^{4} \mathrm{~cm}^{-3}$, and $A_{v}=10 \mathrm{mag}$. The calculated fractional abundances of representative sulfur-containing species are modeled for a cloud age of $5 \times 10^{5} \mathrm{yr}$. Three different models were used. Model 1 was calculated using the UMIST RATE06 dipole-enhanced database (Woodall et al. 2007) with an initial abundance of sulfur $2 \times$ $10^{-8}$ with respect to $\mathrm{H}$. In model 2 the new branching fractions and rates reported here for the DR of $\mathrm{H}_{3} \mathrm{~S}^{+}$were included. Model 3 had an increased $\mathrm{S}$ abundance of $8 \times 10^{-8}$, as used by Smith et al. (2004). In the latter model we also included a higher degree of fragmentation in the DR of some important ions (see Table 1), for which the branching fractions have not been measured. This is suggested by the general observation from storage ring studies that the DR reaction usually leads to a high degree of fragmentation, as in the case of $\mathrm{C}_{2} \mathrm{D}_{5}^{+}$, where even four-body break-up was observed (Geppert et al. 2004). Indeed, this propensity for three-body break-up has been observed for several triatomic ions studied at CRYRING (e.g., Larsson \& Thomas 2001). The fragmentation of $\mathrm{H}_{3} \mathrm{CS}^{+}$is taken to be similar to that reported for the DR of $\mathrm{H}_{3} \mathrm{CO}^{+}$, where the $\mathrm{C}-\mathrm{O}$ bond was preserved in most of the cases (Hamberg et al. 2007), and the branching fractions in the $\mathrm{DR}$ of $\mathrm{HSO}^{+}$were taken from those reported for $\mathrm{HCO}^{+}$. Despite the fact that the channels $\mathrm{H}+\mathrm{S}+\mathrm{O}$ and $\mathrm{S}+\mathrm{OH}$ are both energetically allowed, we included only the first, because the channel $\mathrm{S}+\mathrm{OH}$ requires a large rearrangement of the molecule. Finally, the rate for the reaction $\mathrm{H}_{3}^{+}+\mathrm{CS} \rightarrow \mathrm{HCS}^{+}+\mathrm{H}_{2}$ was increased to $5.7 \times$ $10^{-9}(T / 300)^{-0.6} \mathrm{~cm}^{3} \mathrm{~s}^{-1}$ according to calculations by Adams et al. (1985).

The results of the model calculations for selected sulfur-bearing species are presented in Table 2. For comparison, the first column contains the fractional abundances observed toward TMC-1 (Smith et al. 2004). The agreement of model 3 and the observations is satisfactory, although the discrepancies for $\mathrm{H}_{2} \mathrm{~S}$ and $\mathrm{HCS}^{+}$ are still striking, with the calculated fractional abundances for $\mathrm{HCS}^{+}$being a factor of 100 lower than observations. No improvement is achieved for the $\mathrm{HCS}^{+} / \mathrm{CS}$ ratio, which is $\sim 0.001$ (for discussion see, e.g., Montaigne et al. 2005). The predicted abundances for $\mathrm{SO}$ and $\mathrm{SO}_{2}$ agree well for models 1 and 2, while model 3 has problems reproducing these abundances at the same time: $\mathrm{SO}$ is overproduced by a factor of 4 , and the $\mathrm{SO}_{2}$ abundance is a factor of 5 lower than observed. In contrast, the fractional abundances of $\mathrm{H}_{2} \mathrm{CS}, \mathrm{CS}, \mathrm{OCS}, \mathrm{C}_{2} \mathrm{~S}$, and $\mathrm{C}_{3} \mathrm{~S}$ are reproduced well by gas-phase reactions.

The improved agreement for $\mathrm{H}_{2} \mathrm{~S}$ in model 3 is primarily due to the higher elemental sulfur abundance adopted in this model. In theory, we could increase the sulfur abundance even more to 
TABLE 2

Fractional Abundances of Sulfur-bearing Compounds

\begin{tabular}{|c|c|c|c|c|}
\hline Species & TMC-1 & Model 1 & Model 2 & Model 3 \\
\hline $\mathrm{H}_{2} \mathrm{~S} \ldots \ldots \ldots$ & $5(-10)$ & $1.3(-11)$ & $4.0(-12)$ & $1.7(-11)$ \\
\hline $\mathrm{H}_{2} \mathrm{CS} \ldots \ldots$ & $7(-10)$ & $3.2(-10)$ & $3.2(-10)$ & $7.4(-10)$ \\
\hline $\mathrm{HCS}^{+}$. & $4(-10)$ & $8.1(-13)$ & $8.1(-13)$ & $3.0(-12)$ \\
\hline CS....... & $4(-09)$ & $1.5(-09)$ & $1.5(-09)$ & $3.5(-09)$ \\
\hline SO ....... & $2(-09)$ & $3.2(-09)$ & $3.2(-09)$ & $9.1(-09)$ \\
\hline OCS.... & $2(-09)$ & $5.3(-10)$ & $5.3(-10)$ & $2.4(-09)$ \\
\hline $\mathrm{SO}_{2} \ldots \ldots \ldots \ldots \ldots \ldots \ldots \ldots \ldots \ldots \ldots$ & $1(-09)$ & $6.2(-10)$ & $6.2(-10)$ & $1.8(-10)$ \\
\hline $\mathrm{C}_{2} \mathrm{~S}$ & $8(-09)$ & $1.4(-09)$ & $1.4(-09)$ & $5.7(-09)$ \\
\hline $\mathrm{C}_{3} \mathrm{~S} \ldots \ldots \ldots \ldots \ldots \ldots \ldots \ldots \ldots \ldots \ldots \ldots \ldots$ & $1(-09)$ & $5.2(-10)$ & $5.2(-10)$ & $2.1(-09)$ \\
\hline
\end{tabular}

NoTE.-Calculated fractional abundances of representative sulfur-bearing compounds with respect to $\mathrm{H}_{2}$ at $5 \times 10^{5} \mathrm{yr}$, compared with observed values for TMC-1 for the gas-phase dark cloud model. We use $\mathrm{A}(-\mathrm{B})$ notation for $\mathrm{A} \times 10^{-\mathrm{B}}$.

reproduce the observations of $\mathrm{H}_{2} \mathrm{~S}$ and $\mathrm{HCS}^{+}$, but then the abundances of the other sulfur-bearing species would no longer agree. We must therefore look to another mechanism for the formation of $\mathrm{H}_{2} \mathrm{~S}$. As discussed above, it has long been postulated that the enhanced abundances of $\mathrm{H}_{2} \mathrm{~S}$ seen in warmer gas around protostars is due to grain surface formation followed by evaporation (e.g., Hatchell et al. 1999; Vastel et al. 2003). The laboratory results and model predictions above provide strong evidence that gas-grain interactions are also important in dark clouds at $10 \mathrm{~K}$.

\subsection{Deuterium Chemistry and Gas-Grain Interactions}

We have therefore considered the effect of these new branching fractions on models that include deuterium chemistry and interaction with the dust grains. The model described in Roberts et al. (2004) has been updated with rate coefficients from RATE06 and extended to include reactions of species on grain surfaces (via the "modified rate equation" method; see Caselli et al. 1998). Note that, in contrast to the models presented by Marcelino et al. (2005), we assume statistical branching fractions for the DR reactions of deuterated molecular ions unless there is experimental evidence to the contrary. Furthermore, only the fractionation reactions listed in Roberts et al. (2004) are included, so there is no direct fractionation of the $\mathrm{H}_{3} \mathrm{CS}^{+}$and $\mathrm{H}_{3} \mathrm{~S}^{+}$ions. For comparison with the purely gas-phase models above, a constant temperature of $10 \mathrm{~K}$ is adopted, and $\mathrm{H}_{2}$ density of $10^{4} \mathrm{~cm}^{-3}$. The only mechanism included to return frozen species to the gas-phase is thermal desorption, and this process is ineffective at $10 \mathrm{~K}$ (except for $\mathrm{H}, \mathrm{D}$, and $\mathrm{He}$ ).

Three models have been run, analogous to models $1-3$ above and labeled 1a, $2 \mathrm{a}$, and $3 \mathrm{a}$. Results at $2.5 \times 10^{5} \mathrm{yr}$ are shown in Table 3, although it is difficult to find one time of best agreement; the $\mathrm{SO}$ and $\mathrm{SO}_{2}$ abundances only begin to rise after $\sim 10^{5} \mathrm{yr}$, when the abundances of most other species are falling. Figures 4 and 5 show the evolution of fractional abundances and molecular $\mathrm{D} / \mathrm{H}$ ratios over time for models $2 \mathrm{a}$ and $3 \mathrm{a}$.

Comparing model $2 \mathrm{a}$ to Model 1a shows the effect of including the new branching fractions for the $\mathrm{H}_{3} \mathrm{~S}^{+}$recombination. As expected, this reduces the $\mathrm{D}_{2} \mathrm{~S} / \mathrm{H}_{2} \mathrm{~S}$ ratio and the $\mathrm{H}_{2} \mathrm{~S}$ abundance in the gas phase. In model $3 \mathrm{a}$, the gas-phase $\mathrm{H}_{2} \mathrm{~S}$ abundance has recovered somewhat, but it is still lower than that observed toward TMC-1. The deuterium fractionation in model $3 \mathrm{a}$ is very similar to model 2a. As Figures 4 and 5 show, the fractionation of HDS in the gas phase does become very high $(0.1)$ at $\sim 10^{6} \mathrm{yr}$, which is due to the freeze-out of $\mathrm{CO}$ (discussed above), but this is a shortlived effect, and the absolute abundances of HDS and $\mathrm{H}_{2} \mathrm{~S}$ are orders of magnitude lower than observed.
TABLE 3

Fractional Abundances and D/H Ratios for Models Including Deuterium Chemistry AND Dust

\begin{tabular}{|c|c|c|c|c|}
\hline Species & TMC-1 & Model 1a & Model 2a & Model 3a \\
\hline $\mathrm{H}_{2} \mathrm{~S}$ & $5(-10)$ & $6.7(-11)$ & $1.2(-12)$ & $2.2(-11)$ \\
\hline $\mathrm{H}_{2} \mathrm{CS}$ & $7(-10)$ & $1.6(-11)$ & $1.9(-12)$ & $4.2(-10)$ \\
\hline $\mathrm{HCS}^{+} \ldots \ldots \ldots \ldots \ldots \ldots \ldots$ & $4(-10)$ & $1.1(-13)$ & $6.8(-13)$ & $2.5(-12)$ \\
\hline CS $\ldots \ldots \ldots \ldots \ldots \ldots \ldots \ldots \ldots \ldots \ldots \ldots \ldots \ldots \ldots \ldots \ldots$ & $4(-09)$ & $4.8(-11)$ & $6.9(-10)$ & $1.5(-9)$ \\
\hline $\mathrm{SO}$ & $2(-09)$ & $1.9(-09)$ & $1.2(-9)$ & $3.5(-9)$ \\
\hline 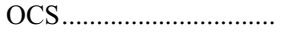 & $2(-09)$ & $3.4(-11)$ & $1.6(-10)$ & $1.7(-9)$ \\
\hline $\mathrm{SO}_{2} \ldots \ldots \ldots \ldots \ldots \ldots \ldots \ldots \ldots \ldots \ldots \ldots \ldots \ldots \ldots \ldots$ & $1(-09)$ & $4.8(-10)$ & $1.2(-10)$ & $3.8(-10)$ \\
\hline $\mathrm{C}_{2} \mathrm{~S}$ & $8(-09)$ & $2.3(-11)$ & $7.4(-10)$ & $2.9(-9)$ \\
\hline $\mathrm{C}_{3} \mathrm{~S}$ & $1(-09)$ & $2.3(-11)$ & $3.3(-10)$ & $1.3(-9)$ \\
\hline $\mathrm{HDS} / \mathrm{H}_{2} \mathrm{~S} \ldots \ldots \ldots \ldots \ldots \ldots \ldots \ldots$ & & 0.2 & 0.04 & 0.05 \\
\hline $\mathrm{D}_{2} \mathrm{~S} / \mathrm{H}_{2} \mathrm{~S}$ & & 0.007 & 0.0001 & 0.0004 \\
\hline $\mathrm{HDCS} / \mathrm{H}_{2} \mathrm{CS} \ldots \ldots \ldots \ldots \ldots . . . . . .$. & 0.02 & 0.04 & 0.05 & 0.05 \\
\hline $\mathrm{D}_{2} \mathrm{CS} / \mathrm{H}_{2} \mathrm{CS} \ldots \ldots \ldots \ldots \ldots \ldots$ & & 0.0003 & 0.0006 & 0.0006 \\
\hline
\end{tabular}

Note.-Calculated fractional abundances of sulfur-bearing compounds and molecular $\mathrm{D} / \mathrm{H}$ ratios for the models including deuterium chemistry and interaction with dust grains; $T=10 \mathrm{~K}, n\left(\mathrm{H}_{2}\right)=10^{4} \mathrm{~cm}^{-3}$, time step $=2.5 \times 10^{5} \mathrm{yr}$. We use $\mathrm{A}(-\mathrm{B})$ notation for $\mathrm{A} \times 10^{-\mathrm{B}}$.

In all models, however, significant quantities of $\mathrm{H}_{2} \mathrm{~S}$, HDS, and $\mathrm{D}_{2} \mathrm{~S}$ are synthesized on the grain surfaces via $\mathrm{H}$ addition to $\mathrm{S}$ atoms (see Figs. 4 and 5). The $\mathrm{HDS} / \mathrm{H}_{2} \mathrm{~S}$ and $\mathrm{D}_{2} \mathrm{~S} / \mathrm{H}_{2} \mathrm{~S}$ ratios on the grain surfaces are less affected by the rate coefficients/ branching fractions used in the gas-phase sulfur chemistry, since they depend on the atomic $\mathrm{D} / \mathrm{H}$ ratio. This reaches 0.1 at $\sim 10^{6} \mathrm{yr}$, which is not quite high enough to reproduce the observations of HDS and $\mathrm{D}_{2} \mathrm{~S}$ toward protostellar sources, but previous modeling work (e.g., Roberts et al. 2003, 2004) has shown that higher densities $\left(\sim 10^{6} \mathrm{~cm}^{-3}\right)$ further enhance deuterium fractionation, particularly for $\mathrm{H}_{3}^{+}$and atomic $\mathrm{H}$.

The overall agreement of model $3 \mathrm{a}$ with observations is similar to the gas-phase model 3. The $\mathrm{HDCS} / \mathrm{H}_{2} \mathrm{CS}$ ratio of 0.02 and $\mathrm{H}_{2} \mathrm{CS}$ abundance of $7 \times 10^{-10}$, seen toward TMC-1 (Minowa et al. 1997 ), are reproduced by all models for times between $\sim 2 \times 10^{4}$ and $10^{5} \mathrm{yr}$. To date, $\mathrm{D}_{2} \mathrm{CS}$ has been detected toward one source, Barnard 1 (Marcelino et al. 2005); the observed $\mathrm{D}_{2} \mathrm{CS} / \mathrm{H}_{2} \mathrm{CS}$ ratio is $\sim 0.1$, and the $\mathrm{HDCS} / \mathrm{H}_{2} \mathrm{CS}$ ratio is 0.3 . This fractionation is higher than predicted by the models either in the gas phase or on the grain surfaces.

At present, there is no mechanism in these models to return the $\mathrm{H}_{2} \mathrm{~S}$ (and other species) synthesized on the grains to the gas phase. Several nonthermal desorption mechanisms have been postulated, however (see e.g., Willacy \& Millar 1998; Garrod et al. 2007; Roberts et al. 2007), which could be important in dark clouds. Based on Figure 5, only $\sim 0.5 \%$ of the $\mathrm{H}_{2} \mathrm{~S}$ formed on the grain surface would have to be returned to the gas phase in order to reproduce the abundance observed toward TMC-1.

\section{CONCLUSIONS}

In the DR of $\mathrm{H}_{3} \mathrm{~S}^{+}$, the main production channel leads to the formation of $\mathrm{HS}+2 \mathrm{H}$, whereas $\mathrm{H}_{2} \mathrm{~S}+\mathrm{H}$ is only a minor pathway. A similar result was reported for the analogous channels in the DR of $\mathrm{H}_{3} \mathrm{O}^{+}$(Neau et al. 2000). The overall value for the reaction rate coefficient, $2.8 \times 10^{-7}$ at $300 \mathrm{~K}$, is reasonable for small, hydrogenated molecular ions. Model calculations of the dark cloud TMC-1, using the UMIST code incorporating these new results, deliver a good agreement with observations for many also deuterated interstellar sulfur compounds. However, large discrepancies are found for, e.g., $\mathrm{H}_{2} \mathrm{~S}$ and $\mathrm{HCS}^{+}$, which are grossly underestimated in both gas-phase and gas-grain models. Whereas models 

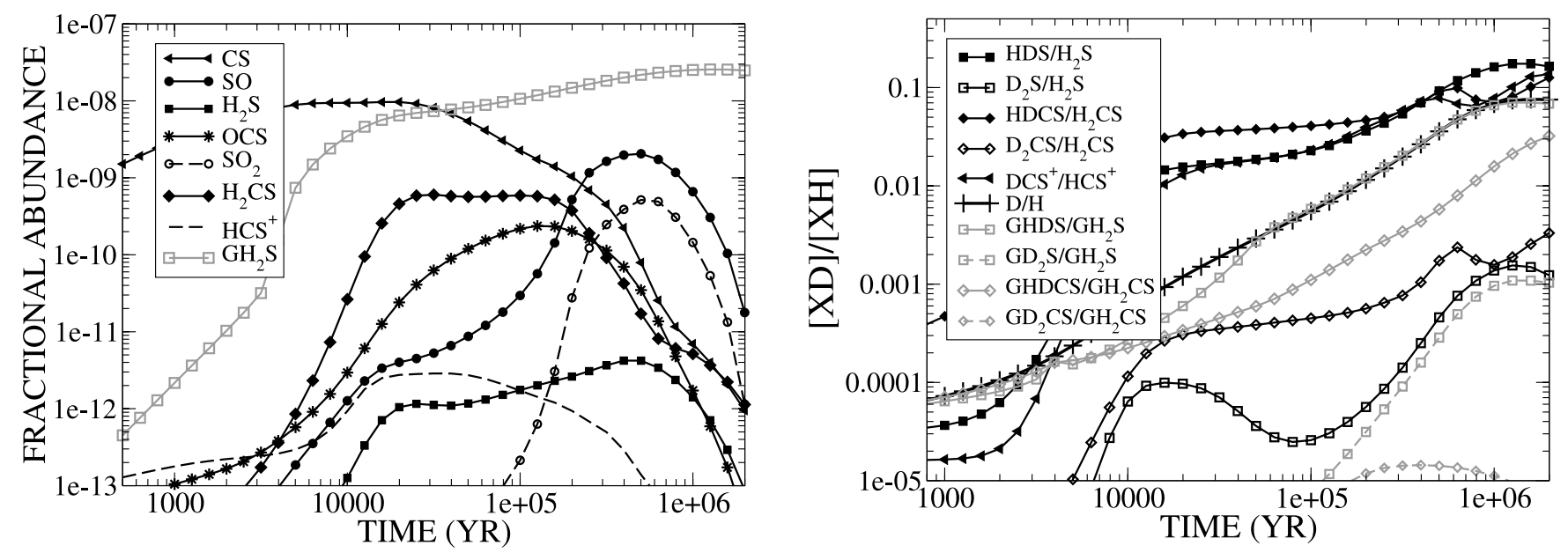

FIG. 4.- Results for model calculations including deuterium chemistry and interaction with dust grains, showing model 2 a fractional abundances (left) and molecular $\mathrm{D} / \mathrm{H}$ ratios (right). Prefix G indicates surface species. [See the electronic edition of the Journal for a color version of this figure.]
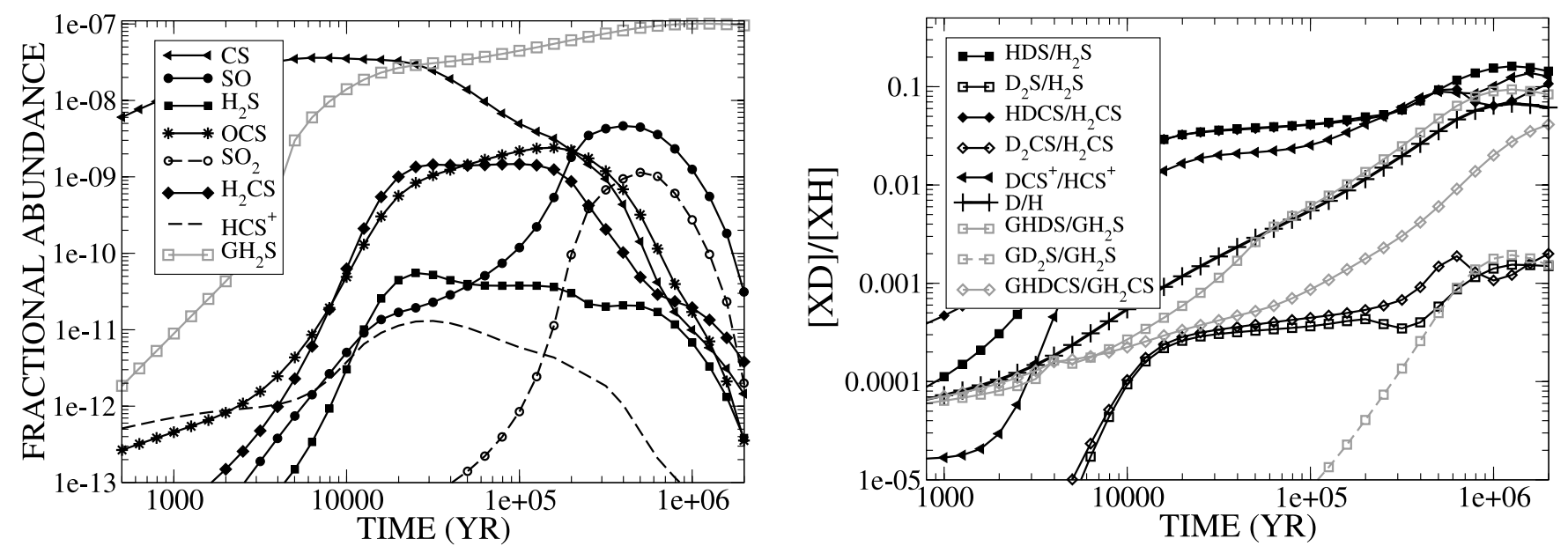

FIG. 5.- Results for model calculations including deuterium chemistry and interaction with dust grains, showing model 3 a fractional abundances (left) and molecular $\mathrm{D} / \mathrm{H}$ ratios (right). Prefix G indicates surface species. [See the electronic edition of the Journal for a color version of this figure.] 
incorporating grain surface reactions produce a large quantity on these surfaces, at the low temperatures encountered in dark clouds, the desorption mechanisms used in the model are inefficient in transferring the species to the gas phase once they are formed.

The authors are grateful to the staff members of Manne Siegbahn Laboratory for technical assistance during the experiment. M. K. is thankful to the Swedish Institute for the financial support, and together with J. S. acknowledges support by the Ministry of Science and Higher Education, Poland (grant N202 111 31/1194). W. D. G. gratefully acknowledges support from the Swedish Research Council (contract 2006-427) and the Swedish Space Board (grant 76/06). This work was supported by the Swedish Research Council. Astrophysics at QUB is supported by a grant from the STFC. C. W. acknowledges DEL for a studentship.

\section{APPENDIX}

$$
T_{\mathrm{D}_{3} \mathrm{~S}^{+}}=\left(\begin{array}{cccc}
t(1-t) L_{\alpha}^{*} & 2 t(1-t)^{2} & 0 & t(1-t)^{2} L_{\delta}^{*} \\
0 & t^{2}(1-t) & t(1-t) L_{\gamma}^{*} & t(1-t)^{2} L_{\delta}^{*}+t(1-t) L_{\delta} \\
0 & 0 & 0 & t^{2}(1-t) L_{\delta}^{*} \\
0 & 0 & 0 & t(1-t)^{2} L_{\delta}^{*}+t(1-t) L_{\delta} \\
0 & t(1-t)^{2} & t(1-t) L_{\gamma}^{*}+t L_{\gamma} & t^{2}(1-t) L_{\delta}^{*} \\
t(1-t) L_{\alpha}^{*}+t L_{\alpha} & 2 t^{2}(1-t) & 0 & t^{2}(1-t) L_{\delta}^{*}+t^{2} L_{\delta} \\
t^{2} L_{\alpha}^{*} & t^{3} & t^{2} L_{\gamma}^{*} & t^{3} L_{\delta}^{*}
\end{array}\right)
$$

where $L_{\alpha}^{*}=1-L_{\alpha}, L_{\gamma}^{*}=1-L_{\gamma}$, and $L_{\delta}^{*}=1-L_{\delta}$.

Abouelaziz, H., et al. 1992, Chem. Phys. Lett., 194, 263

Adams, N. G., \& Smith, D. 1988, Chem. Phys. Lett., 144, 11

Adams, N. G., Smith, D., \& Clary, D. C. 1985, ApJ, 296, L31

Adams, N. G., et al. 1991, J. Chem. Phys., 94, 4852

Bardsley, J. N. 1968, J. Phys. B, 1, 365

Bates, D. R. 1986, ApJ, 306, L45 1991, J. Phys. B, 24, 3267

Caselli, P., Hasegawa, T. I., \& Herbst, E. 1998, ApJ, 495, 309

Datz, S., et al. 1995a, Phys. Rev. Lett., 74, 896 1995b, Phys. Rev. A, 52, 2901

Galloway, E. T., \& Herbst, E. 1991, ApJ, 376, 531

Garrod, R. T., Wakelam, V., \& Herbst, E. 2007, A\&A, 467, 1103

Geppert, W. D., et al. 2004, Phys. Rev. Lett., 93, 153201

Haider, S. A., \& Bhardwaj, A. 2005, Icarus, 171, 196

Hamberg, M., et al. 2007, Mol. Phys., 105, 899

Hatchell, J., Roberts, H., \& Millar, T. J. 1999, A\&A, 346, 227

Herbst, E. 2003, New OSU Standard Model (Columbus: OSU Physics Dept.), http://www.physics.ohio-state.edu/ eric

- 2007, New OSU Standard Model (Columbus: OSU Physics Dept.), http://www.physics.ohio-state.edu/ eric

Herbst, E., DeFrees, D. J., \& Koch, W. 1989, MNRAS, 237, 1057

Jensen, M. J., et al. 1999, Phys. Rev. A, 60, 2970

. 2000, ApJ, 543, 764

Kilgus, G., et al.,1992, Phys. Rev. A, 46, 5730

Lampert, A., et al.,1996, Phys. Rev. A, 53, 1413

Larsson, M. 1997, Ann. Rev. Phys. Chem., 48, 151

Larsson, M., \& Thomas, R. D. 2001, Phys. Chem. Chem. Phys., 3, 4471

Le Teuff, Y. H., Millar, T. J., \& Markwick, A. J. 2000, A\&AS, 146, 157

Lodders, K. 2004, ApJ, 611, 587

Lucas, R., \& Liszt, H. S. 2002, A\&A, 384, 1054

Marcelino, N., Cernicharo, J., Roueff, E., Gerin, M., \& Mauersberger, R. 2005, ApJ, 620, 308

Martín, S., Martín-Pintado, J., Mauersberger, R., Henkel, C., García-Burillo, S. 2005, ApJ, 620, 210

Millar, T. J., \& Herbst, E. 1990, A\&A, 231, 466

Minh, Y. C., Irvine, W. M., \& Ziurys, L. M. 1989, ApJ, 345, L63

Minh, Y. C., Ziurys, L. M., Irvine, W. M., \& McGonagle, D. 1990, ApJ, 360, 136

\section{REFERENCES}

Minowa, H., Satake, M., Hirota, T., \& Yamamoto, S. 1997, ApJ, 491, L63

Montaigne, H., et al. 2005, ApJ, 631, 653

Mowat, J. R., et al. 1995, Phys. Rev. Lett., 74, 50

Neau, A., et al. 2000, J. Chem. Phys., 113, 1762

Ohishi, M., \& Kaifu, N. 1998, Faraday Discuss., 109, 205,

Öjekull, J., et al. 2004, J. Chem. Phys., 120, 7391

Paál, A., Simonsson, A., Källberg, A., Dietrich, J., \& Mohos, I. 2004, Proc. EPAC 2004 (Lucerne: EPS-AG), 2745

Parise, B., et al. 2002, A\&A, 393, L49 2004, A\&A, 416, 159

Peterson, J. R., et al. 1998, J. Chem. Phys., 108, 1978

Prasad, S. S., \& Huntress, T. J., Jr. 1982, ApJ, 260, 590

Roberts, H., Herbst, E., \& Millar, T. J. 2003, ApJ, 591, L41 2004, A\&A, 424, 905

Roberts, J. F., Rawlings, J. M. C., Viti, S., \& Williams, D. A. 2007, MNRAS, 382,733

Rodgers, S. D., \& Charnley, S. B. 2002, MNRAS, 330, 660

Roueff, E., Tiné, S., Coudert, L. H., Pineau des Forêts, G., Falgarone, E., \& Gerin, M. 2000, A\&A, 354, L63

Rowe, B. R., Canosa, A., \& Le Page, V. 1995, Int. J. Mass Spectrosc., 149/150, 573

Semaniak, J., et al. 1998, ApJ, 498, 886

Smith, W. M., Herbst, E., \& Chang, Q. 2004, MNRAS, 350, 323

Thomas, R., et al. 2002, Phys. Rev. A, 66, 032715F

Wakelam, V., Castets, A., Ceccarelli, C., Lefloch, B., Caux, E., \& Pagani, L. 2004, A\&A, 413, 609

Wigner, E. P. 1948, Phys. Rev., 73, 1002

Willacy, K., \& Millar, T. J. 1998, MNRAS, 298, 562

Woodall, J., Agúndez, M., Markwick-Kemper, A. J., \& Millar, T. J. 2007, A\&A, 466, 1197

van der Tak, F. F. S., Boonman, A. M. S., Braakman, R., \& van Dishoeck, E. F. 2003, A\&A, 412, 133

van Dishoeck, E. F., Blake, G. A., Jansen, D. J., \& Groesbeck, T. D. 1995, ApJ, 447, 760

Vastel, C., Phillips, T. G., Ceccarelli, C., \& Pearson, J. 2003, ApJ, 593, L97

Zhaunerchyk, V., et al. 2008, Phys. Rev. A, 77, 034701 